\title{
Challenges in the Implementation of Alternative Learning System
}

\author{
Mario E. Campilla, Ed.D., Dr. Freda B. Lopez \\ St. Clare College of Caloocan \\ St. Clare College
}

\section{ABSTRACT}

Every Filipino has a right to free basic education. Hence, the Philippine government through the Department of Education has implemented the Alternative Learning System (ALS) as a crucial component of Philippine education to provide every individual the access to quality basic education to reduce illiteracy rate as envisioned in the Education for All (EFA) 2015 Philippine Plan of Action. Like any other organization, ALS in Urdaneta City has not been spared with challenges and problems. Descriptive research method was used particularly frequency, percentage, and mean to determine the problems encountered by the ALS teachers and learners. There were 7 mobile teachers and 175 learners who answered a questionnaire where some indicators were constructed by the researchers and some were adopted from the study of Mercado (2015). It was found out that the challenges encountered by the teachers were the following: students' tardiness/absenteeism, inability to deliver lesson, unpredictable content of the examination, and unavailability of state of the art equipment. Results also revealed that leading problems encountered by the students were the following: teachers give too much memory works, there is distraction in the learning environment, and they lack basic computer knowledge. The results demonstrate the need for the establishment of interventions that will address the problems encountered by the ALS teachers and learners. Constant monitoring and application of these interventions will lead to the effective teaching and learning process between the teachers and the learners. Like any organizations, Alternative Learning System in Urdaneta City has not been spared from problems and challenges. Based from the results, the following management mechanisms/ interventions were formulated. The leading problems of teacher gives too much memory work, students' tardiness/ absenteeism, teachers' inability to deliver the lesson, unpredictable content of the examination, unavailability of state of the art equipment, there is distraction in the learning environment and students' lack of basic computer knowledge. The proposed management mechanisms/ interventions are preparation of activity sheets/ cards suited to the ability of the learners, constant monitoring of the als learners, one on one tutorial, home visitation, crafting of schedules wherein teacher with the specialization will teach particular topics, coaching and mentoring, demonstration of all mobile teachers with feedbacking, cover all the skills/ competencies intended for als learners, update modules, gathering of data about the coverage of the examination from learners of als who took the exam, strengthen partnership/linkages with different stakeholders, provision of learning centers in the community, separate learning 


\section{$2^{\text {nd }}$ International Conference on}

\section{TEACHING, LEARNING and EDUCATION}

\section{5-17 November, 2019}

\section{Rotterdam, Netherlands}

centers for ALS learners, exposure of students in computers, implementation of computer literacy week wherein different activities will be conducted like computer tutorials on the use of microsoft and invite experts in the field to teach basic computer knowledge/skills

Keywords: Alternative, Challenges, Implementation, Learning, System 